successful treatment of diabetes. Dr. Kleen's directions will well repay study, and we can recommend this volume to those who seek information on all matters connected with glycosuria and diabetes.

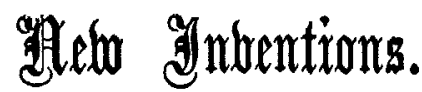

\section{DRILL FOR MASTOID CASES.}

Messrs. Merer and Meltzer have made for me a modified form of drill for mastoid cases shown in the annexed diagram. By the arrangement of toothed wheels I find it quite easy to rotate the burr at 1000 revolutions per minute. The length of the shaft and the shape of the handle enable one to give very accurate directing power and

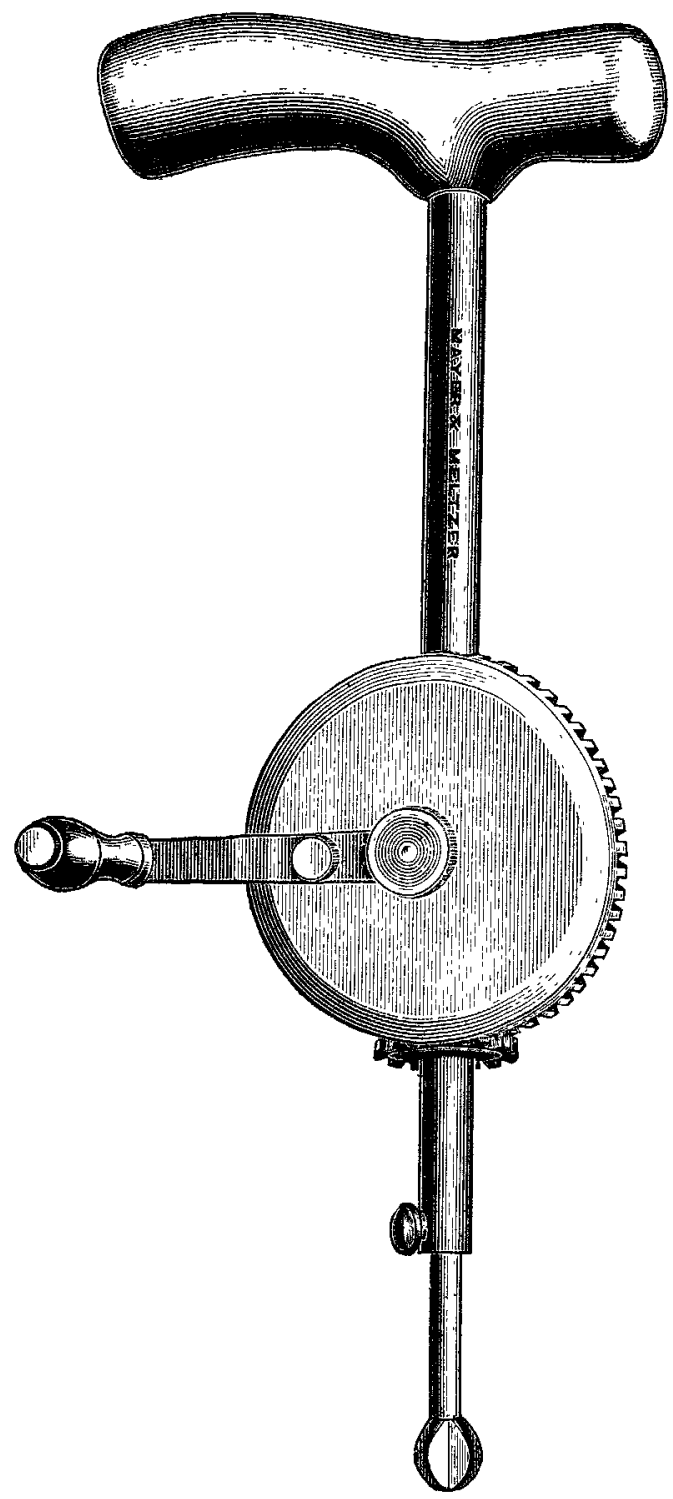

pressure. The burrs fit into a square socket, so that different sizes may be used. While not to be compared, of course, with the dental engine, my drill will be found very useful where the engine is not available or, as in operations in the country, where it is difficult to take the engine with one. The whole length of the drill does not exceed 10 inches, so that it will go easily into the ordinary surgical bag. It is all metal and so can be made quite aseptic.

Soarborough. SIDNEY H. SNELL, M.D., B.S. Lond.

\section{ASEPTIO SURGIOAL DRESSINGS.}

THE feature of some new sterilised dressings which we have received from Messrs. Robinson and Son, Limited, of Wheat Bridge Mills, Chesterfield, and of 55, Fann-street, London, E.O., is the method by which they are packed for surgeons' use in operation. The dressings are sterilised by steam and packed in cases all sterilised in the following manner. The dressings are cut and folded to the size required and then inclosed in the patent container which consists of an inner wrapper of parchment paper. Outside this is a wrapper of grey waterproof wool and outside this, again, is an onter wrapper of glazed paper. The whole is sterilised by means of steam under pressure. In order to avoid the contents getting moist the apparatus with the dressings inclosed is heated, after shutting off the steam, in a vacuum. The packets are then taken out and sealed under strict aseptic precautions. This step of obviating the appropriation of moisture during the process of sterilisation by steam is of course important, as all surgical dressings are much more effective when used quite dry. We have received two typical samples of cases thus prepared, but amongst the series provided by this firm are an amputation set large and small, a breast cases set, an excision of glands set, a minor operation set, a skin-grafting set, a hernia set, a trephining and mastoid set, and an abdominal section set. Most of these comprise, of course, absorbent sponges absorbent wool, gauze, and bandages. This method of packing aseptic dressings is fully in accordance with surgical requirements.

\section{NEW FRANUM SOISSORS.}

THESE scissors, which I have designed and which Messrs. Mayer and Meltzer have kindly made for me, consist of upper and lower blades. The upper one is fashioned in the ordinary way; the lower blade is much broader and is divided nearly up to the pivot-joint into two portions, with a slight interval between them. The left portion, together with the

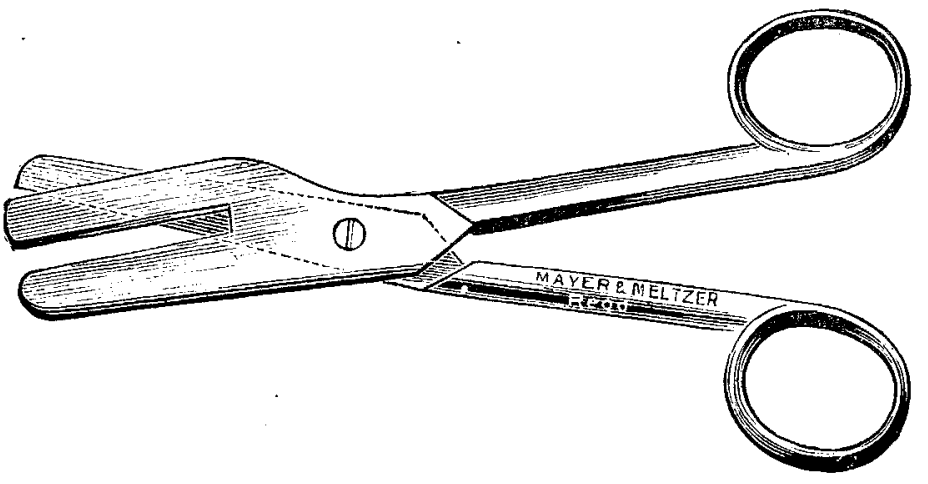

right, form a director and guide, whilst the right portion alone opposes the upper blade and forms the cutting surface. By this means the operation of severing the frænum linguæ can be performed with one hand, whilst there is no danger of wounding the lingual vessels.

E. R. HAINES CORY, M.R.C.S. Eng., L.R.O.P. Lond. Bournemouth.

\section{THE " OLARATMOS" PATENT VENTILATING SCREEN.}

THIS screen effects two things: firstly, it filters the air, and, secondly, it disperses a draught so that the current of incoming air is diffused and no unpleasint cold currents are experienced. It consists simply of a frame containing two sheets of metal gauze of a certain mesh which is easily attached to the ordinary window fittings. Between the pieces of metal ganze is placed, also, a ganze of fabric like Gamgee tissue. If desired this may be impregnated with some antiseptic. In order to place the screen in position the lower sash is raised and the frame is introduced into the grooves provided for the upper sash. The screen is secured by means of wedges at each end. The window can be opened or closed as usual by gently pressing the sash past the rubber flange provided. The screen is so devised as not to interfere with the free passage of incoming air, whilst it filters it from suspended impurities, as is evident from the accumulation of dirt upon it. Again, the screen acts as a resistance and thus prevents a draught. The patentees are Messrs. F. W. Warren and Co., of 340, Harrow-road, London, W. 